\title{
Article \\ Synthesis of Super-Long Carbon Nanotubes from Cellulosic Biomass under Microwave Radiation
}

\author{
Joy Esohe Omoriyekomwan ${ }^{1}$, Arash Tahmasebi ${ }^{2}$, Jian Zhang ${ }^{1}$ and Jianglong Yu ${ }^{1,3, *}$ \\ 1 Key Laboratory of Advanced Coal and Coking Technology of Liaoning Province, \\ School of Chemical Engineering, University of Science and Technology Liaoning, Anshan 114051, China; \\ joyomoriyekomwan@yahoo.com (J.E.O.); zhangjian7216599@163.com (J.Z.) \\ 2 Department of Chemical Engineering, University of Newcastle, Callaghan, NSW 2308, Australia; \\ arash.tahmasebi@newcastle.edu.au \\ 3 Monash Research Institute of Science and Technology (Suzhou Industrial Park), \\ Southeast University-Monash University Joint Graduate School, Suzhou 215000, China \\ * Correspondence: jianglong.yu@monash.edu; Tel.: +86-512-6299-7871
}

Citation: Esohe Omoriyekomwan, J.; Tahmasebi, A.; Zhang, J.; Yu, J. Synthesis of Super-Long Carbon Nanotubes from Cellulosic Biomass under Microwave Radiation. Nanomaterials 2022, 12, 737. https://doi.org/10.3390/ nano12050737

Academic Editor: Werner Blau

Received: 4 January 2022

Accepted: 21 January 2022

Published: 22 February 2022

Publisher's Note: MDPI stays neutral with regard to jurisdictional claims in published maps and institutional affiliations.

Copyright: (C) 2022 by the authors. Licensee MDPI, Basel, Switzerland. This article is an open access article distributed under the terms and conditions of the Creative Commons Attribution (CC BY) license (https:// creativecommons.org/licenses/by/ $4.0 /)$.

\begin{abstract}
This study reports a novel method for synthesizing super-long carbon nanotubes (SL-CNTs) from cellulose via a microwave treatment process without an external catalyst. CNTs with a length of $0.7-2 \mathrm{~mm}$ were obtained via microwave treatment of cellulose biochar temperatures of $1200-1400{ }^{\circ} \mathrm{C}$. Scanning electron microscope (SEM), together with high-resolution transmission electron microscope (HRTEM) results, were used to investigate the changes in the length and morphology of CNTs with respect to treatment temperature. The morphology of CNTs changed from twisted, curved, and threadlike to straight structures. The average length of CNTs after microwave pyrolysis at $600{ }^{\circ} \mathrm{C}$ was approximately $600-1800 \mathrm{~nm}$, which after microwave treatment at $1300{ }^{\circ} \mathrm{C}$ and $1400{ }^{\circ} \mathrm{C}$ increased to about 1-2 mm. X-ray diffractometer (XRD) results confirmed the crystalline structure of CNTs with two prominent peaks at $2 \theta=26.3^{\circ}$ and $2 \theta=43.2^{\circ}$ correlating with the graphite (002) and (100) reflections. The $\mathrm{I}_{\mathrm{D}} / \mathrm{I}_{\mathrm{G}}$ ratio obtained from Raman spectra of the $\mathrm{CNT}$ s decreased to the lowest value of 0.84 after microwave treatment at $1400^{\circ} \mathrm{C}$, implying a high degree of carbon order. The presence of Fe and trace amounts of other elements were confirmed by the energy-dispersive $\mathrm{X}$-ray spectrometer (EDS) and were postulated to have catalyzed the growth of CNTs. The mechanism of the SL-CNTs growth under microwave treatment was proposed and discussed.
\end{abstract}

Keywords: super-long carbon nanotubes; microwave radiation; carbon materials

\section{Introduction}

After their discovery in 1991 [1], carbon nanotubes (CNTs), one of the many allotropic forms of carbon, have been extensively studied. They are known as unique materials due to their exceptional properties, such as mechanical strength, durability greater than steel, electrical conductivity better than copper, and low density, about four times lower than these materials [2]. The use of CNTs in various electrical, lightweight, and high-strength applications is advantageous due to their unique properties, such as high tensile strength and high modulus, as high as $150 \mathrm{GPa}$ and a $1 \mathrm{TPa}$, respectively [3-5]. Despite these unique properties, carbon nanotubes still have significant drawbacks, such as small dimensions and high cost, and non-sustainable synthesis methods that hinder their full potential [2].

Carbon nanotubes have been successfully synthesized using various methods, such as laser ablation [6], chemical vapor deposition (CVD) [2,7-9], arc-discharge [10], catalytic chemical vapor deposition (CCVD), and plasma-enhanced chemical vapor deposition (PECVD) $[3,11,12]$. These methods usually necessitate using metallic catalysts (e.g., Ni, Mo, Fe, Co, etc.) [13-15], substrate [16], and hydrocarbons as carbon sources (e.g., ethane, methane, acetylene, xylene, or a mixture of these) [17]. Generally, catalyst deactivation during the synthesis of CNTs limits their growth and subsequently hinders their practical 
application [2]. This can be overcome by developing a novel method for synthesizing long CNTs to improve their unique properties to realize their full potential for industrial applications. In some applications, the electrical and mechanical properties of CNTs can only be harnessed when they are long; such structures can be used as electrochemical microactuators or stable, highly conducting micro-cables [18].

Super-long carbon nanotubes (SL-CNTs) have gained increasing attention for numerous plausible applications, including sensors $[19,20]$, nanoelectronics $[21,22]$ and multifunctional composites $[23,24]$. The more extended structures improve the thermal and physical properties $[25,26]$. The length of CNTs usually varies in orders of a few tens of nanometers to millimeters, depending on the synthesis conditions. The length of CNTs is an essential parameter in various applications. For instance, the performance of electronic devices and the generation of conductive networks are determined by nanotube length. In applying nanotubes in composite materials, the length of the nanotubes also determines the load transfer efficiency.

The synthesis of SL-CNTs remains a challenge. There have been some attempts by other researchers to produce SL-CNTs. Chakrabati et al. [27,28] synthesized 5-mm-long aligned CNTs. The super-long CNTs were synthesized through water-assisted CVD using $\mathrm{Si} / \mathrm{SiO}_{2}$ wafer, Fe catalyst, at a pressure of $1 \mathrm{~atm}$, with helium $/ \mathrm{H}_{2}(2.5: 1 \mathrm{v} / \mathrm{v})$ as the carrier gas. The carbon source was high-purity (99.99\%) ethylene. SL-CNTs were synthesized at $700{ }^{\circ} \mathrm{C}$ for about $10 \mathrm{~h}$. The CNTs were generated due to the super-saturation of a carbonmetal solution, which induced carbon segregation leading to CNT formation from the catalyst surface. Loiseau and Pascard [29] used the arc-discharge method to synthesize long CNTs. They studied fourteen elements ( $3 \mathrm{~d}$ and $4 \mathrm{f}$ elements), and it was discovered that long nanotubes were produced when $\mathrm{Se}, \mathrm{S}, \mathrm{Sb}$, and $\mathrm{Ge}$ were used. They related the mechanism to the oxidation and electronic state of the elements. Cho et al. [30] used the CVD process to grow long vertically aligned $C N T s$ using an $\mathrm{Al}_{2} \mathrm{O}_{3}$ catalyst. They proposed the root growth mechanism based on the carbon source and real-time photography analysis and observed that the length of CNTs was time and temperature dependent. Ghemes et al. [2] synthesized long, multiwalled carbon nanotubes via the CVD method using iron carbide. They reported that CNTs formed during iron carbide nucleation into the catalyst nanoparticles, while the length of CNTs depended on catalyst nanoparticles' temperature and stability.

Despite the recent achievements in the synthesis of SL-CNTs, the cost remains high due to the complexity of the synthesis methods. Moreover, methods of synthesis of SL-CNTs are not sustainable due to the use of carbon source gases derived from fossil fuels. Further, there is no report on the production of super-long carbon nanotubes (SL-CNTs) from biomass. Biomass is a natural carbon energy source and has gained increasing attention as a precursor [31] to synthesize carbon materials [32,33], such as carbon nanotubes [34]. This study reports a novel and sustainable method of synthesizing super-long carbon nanotubes (SL-CNTs) from biomass under microwave treatment. Microwave-assisted synthesis has been reported to provide efficient and selective heating arising from electromagnetic energy conversion into thermal energy on a molecular scale. This novel method does not require any external catalysts or carbon sources. Various standard techniques were used to investigate the composition and structure of the super-long nanotubes and to propose their mechanisms of formation and growth.

\section{Materials and Methods}

\subsection{Materials}

Cellulose derived from palm kernel shell (PKS) biomass was used as the feedstock in this study. PKS, purchased from Malaysia, was ground into a size fraction of 150-280 $\mu \mathrm{m}$ and subjected to the cellulose isolation method. The palm kernel shell sample was composed of 33.04 wt.\% cellulose, 45.59 wt.\% lignin, $23.82 \mathrm{wt} \% \%$ hemicellulose, and extractives 9.89 wt.\% [35]. The chemical used and the step-by-step isolation method of PKS components have been reported in our previous study [35]. After isolation, ASTM standards for $\alpha$-cellulose (ASTM D 1103-60) were used to verify the cellulose composition. The cellulose 
bio-component was oven-dried for $12 \mathrm{~h}$ at $80^{\circ} \mathrm{C}$ to eliminate moisture. Activated carbon (AC) was used as the microwave receptor since PKS biomass is a poor microwave absorber. The particle size of the AC used was in the range of 300-600 $\mu \mathrm{m}$ for easy separation by sieving from cellulose after microwave treatment.

\subsection{Microwave-Induced Synthesis of SL-CNTs}

In the first step, CNTs were synthesized from the cellulose sample under fast microwave pyrolysis. Cellulose pyrolysis was conducted in a temperature-programmed microwave oven (Tangshan Microwave Thermal Instrument CO. Ltd., Tangshan, China), operating at a frequency of $2.45 \mathrm{GHz}$ and maximum power output of $2000 \mathrm{~W}$. The cellulose sample was mixed with a microwave receptor (activated carbon) at the ratio of 10:2 to reach the desired pyrolysis temperatures of $600^{\circ} \mathrm{C}$. The mixture of biomass and AC was loaded into a quartz reactor and placed in the microwave oven. A thermocouple was placed inside the reactor to monitor the sample temperature at $2 \mathrm{~s}$ intervals. High purity nitrogen gas $(99.999 \%)$ at $400 \mathrm{~mL} / \mathrm{min}$ flow rate was purged through the system for at least $30 \mathrm{~min}$ to eliminate air before experiments in a $\mathrm{N}_{2}$ atmosphere. Microwave pyrolysis runs were carried out for $30 \mathrm{~min}$. After the pyrolysis, the cellulose char, which contained CNTs, was collected after separation from the AC by sieving.

In the second synthesis step, high-temperature microwave treatment was used to obtain SL-CNTs. About $5 \mathrm{~g}$ of cellulose char was loaded in a ceramic crucible and placed into a larger custom-made quartz reactor (high-temperature resistant). A high-temperature thermocouple was placed inside the reactor to monitor the sample temperature. At $400 \mathrm{~mL} / \mathrm{min}$, nitrogen gas (99.999\%) was purged through the system for at least 20 min to eliminate air before experiments in the $\mathrm{N}_{2}$ atmosphere. Microwave treatment runs were conducted for $30 \mathrm{~min}$ at the desired temperatures of $1200^{\circ} \mathrm{C}, 1300{ }^{\circ} \mathrm{C}$, and $1400{ }^{\circ} \mathrm{C}$.

\subsection{Characterization of Carbon Nanotubes}

The surface morphology of CNTs was studied using scanning electron microscopy (SEM, ZEISS Sigma HD, Oberkochen, Germany). The image measurement was obtained using an in-lens detector at an energy of $2 \mathrm{kV}$ to achieve a clear image (clear visualization). The CNTs were also analyzed with a high-resolution transmission electron microscope (HRTEM) (Fei Tecnai F20) equipped with energy-dispersive X-ray spectroscopy (EDS). The system was set at an accelerating voltage of $120 \mathrm{kV}$, and images were acquired digitally by a high-resolution camera. The obtained images were processed with digital micrograph [36,37]. The length of the CNTs was measured with ImageJ software using direct imaging from the SEM. Image-processing software such as ImageJ has been used to estimate particle length. This software provides accurate length and diameter measurements [38]. The CNT size and length range of the CNTs were obtained from different particles. The diameter of the CNTs was also measured. The composition and carbon microstructure of the CNTs were also analyzed using a high-resolution transmission electron microscope (HRTEM) (Fei Tecnai F20) equipped with energy-dispersive X-ray spectroscopy (EDS). Rietveld refinement quantitative analysis was used to analyze the crystallinity of biochar. The Rietveld method entails quantification analysis established by an internal crystalline standard. The X-ray powder diffraction (in this case, silica powder) is used to estimate amorphous phase content. The peak shape formations, microstructural parameters, peak shape formations, crystal structure information, and background contribution were used to determine the diffraction profile. The crystalline phase of the weight fraction was calculated using Equation (1):

$$
w_{i, c}=w_{i} \frac{w_{s, w}}{w_{s}}\left(\frac{1}{1-w_{s}}\right)
$$

where $w_{i}$ and $w_{s}$ represent refined weight portions of phase $I$ and the internal standard, respectively, $w_{i, c}$ symbolize the original weight portions of phase $i$, and $w_{s, w}$ depicts the initial weight of the internal standard. The composition of the inorganic matter in cellulose was analyzed using X-ray fluorescence (XRF) (Thermo Fisher Scientific, Zurich Switzer- 
land), and the results are shown in Table 1. The PKS cellulose contained high amounts of $\mathrm{Ca}, \mathrm{Fe}$, and $\mathrm{Si}$ and trace amounts of other elements. The crystalline structure of CNTs was investigated with a Rigaku Ultima IV X-ray diffractometer (XRD, Japan). Raman spectroscopy fitted with a laser diode of $532 \mathrm{~nm}$ (Horiba Jobin Yvon Xplora plus, Horiba Scientific, Shanghai, China) was used to study the changes in carbon ordering of CNTs with respect to temperature. The Raman spectra of samples were recorded in a wavenumber range of $500-3500 \mathrm{~cm}^{-1}$ with an acquisition time of $3 \mathrm{~min}$.

Table 1. Chemical composition of PKS cellulose ash obtained by XRF analysis.

\begin{tabular}{cc}
\hline Biomass Element & Weight (\%) \\
\hline Mg & 1.80 \\
$\mathrm{Al}$ & 3.95 \\
$\mathrm{Si}$ & 72.10 \\
$\mathrm{P}$ & 0.50 \\
$\mathrm{~K}$ & 2.10 \\
$\mathrm{Ca}$ & 3.60 \\
$\mathrm{Fe}$ & 11.62 \\
\hline
\end{tabular}

\section{Results and Discussion}

\subsection{Morphology and Microstructure of Carbon Nanotubes}

Figure 1 shows the SEM images of the CNTs formed at $600{ }^{\circ} \mathrm{C}$. The CNTs exhibited twisted, curved, and threadlike morphology on the cellulose char particles. The length and diameter of CNTs were in the range of 600-1800 nm and 50-100 nm, respectively. The EDS results displayed in Figure $1 \mathrm{~d}$ revealed high carbon content in the CNTs, and trace amounts of $\mathrm{Si}, \mathrm{Ca}, \mathrm{K}$, and $\mathrm{Na}$. The inorganic matter was believed to have originated from cellulose since no external material was used in the process.

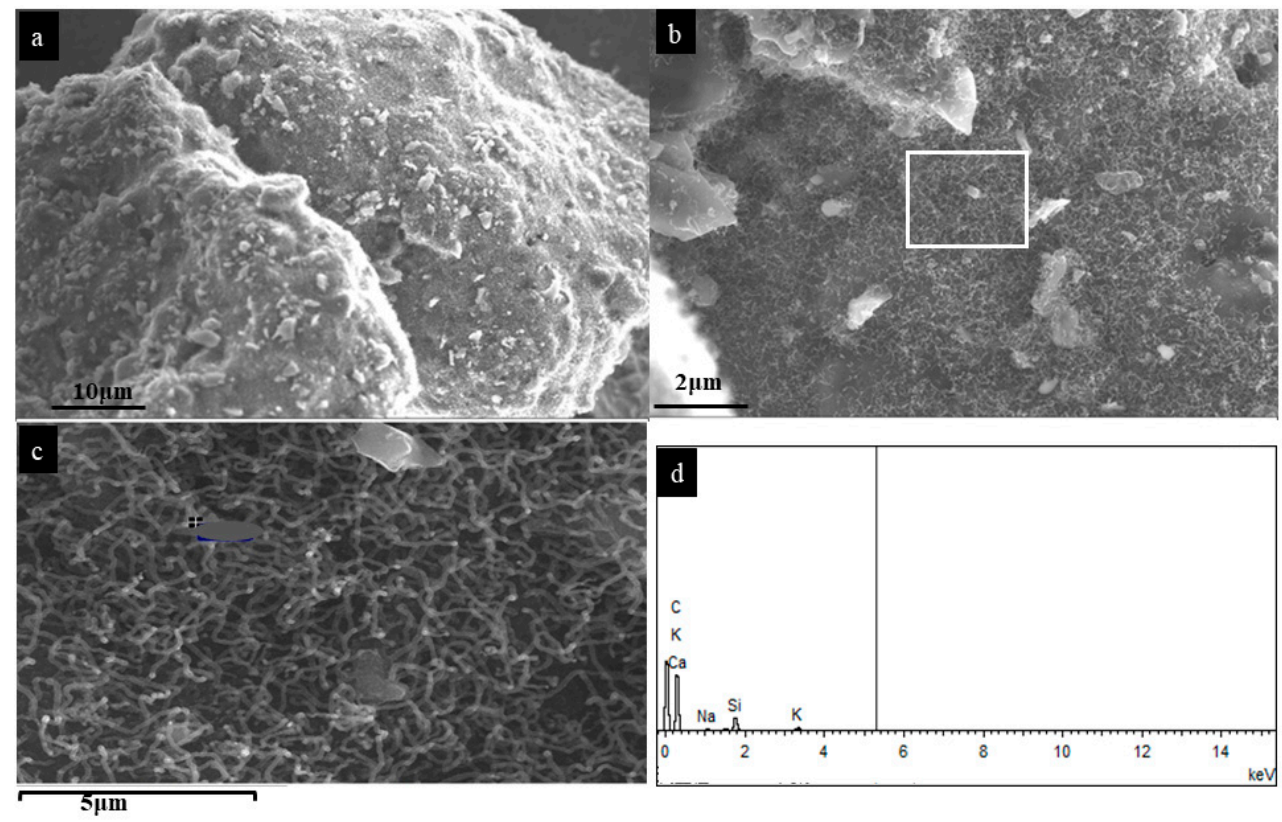

Figure 1. SEM of (a) grown CNTs at $600{ }^{\circ} \mathrm{C},(\mathbf{b})$ magnified image, (c) magnified image of marked section in (b), (d) EDS spectra from (c) image.

The morphology of the SL-CNTs after microwave treatment is presented in Figure 2, showing a dramatic change in the morphology of the CNTs after treatment at $1200{ }^{\circ} \mathrm{C}$, $1300^{\circ} \mathrm{C}$, and $1400^{\circ} \mathrm{C}$. Figure $2 \mathrm{a}$ shows that significant changes in the length and morphology of the CNTs took place after treatment at $1200{ }^{\circ} \mathrm{C}$. However, at this temperature, the CNTs were still twisted and randomly entangled. With further increase in the treatment 
temperature to $1300^{\circ} \mathrm{C}$ and $1400^{\circ} \mathrm{C}, \mathrm{CNT}$ became straight and longer (Figure $2 \mathrm{~b}, \mathrm{c}$ ). An average diameter of approximately $300 \mathrm{~nm}$ and lengths ranging from $0.7-2 \mathrm{~mm}$ were measured. To our knowledge, this is the longest CNT synthesized directly from biomass without the addition of an external catalyst. The CNT's contour length and endpoints were traced using the freehand tool in ImageJ to measure long twisted CNTs. The SEM images used for measurement and the obtained length measurements are shown in Figure 3 and Table 2 , respectively.
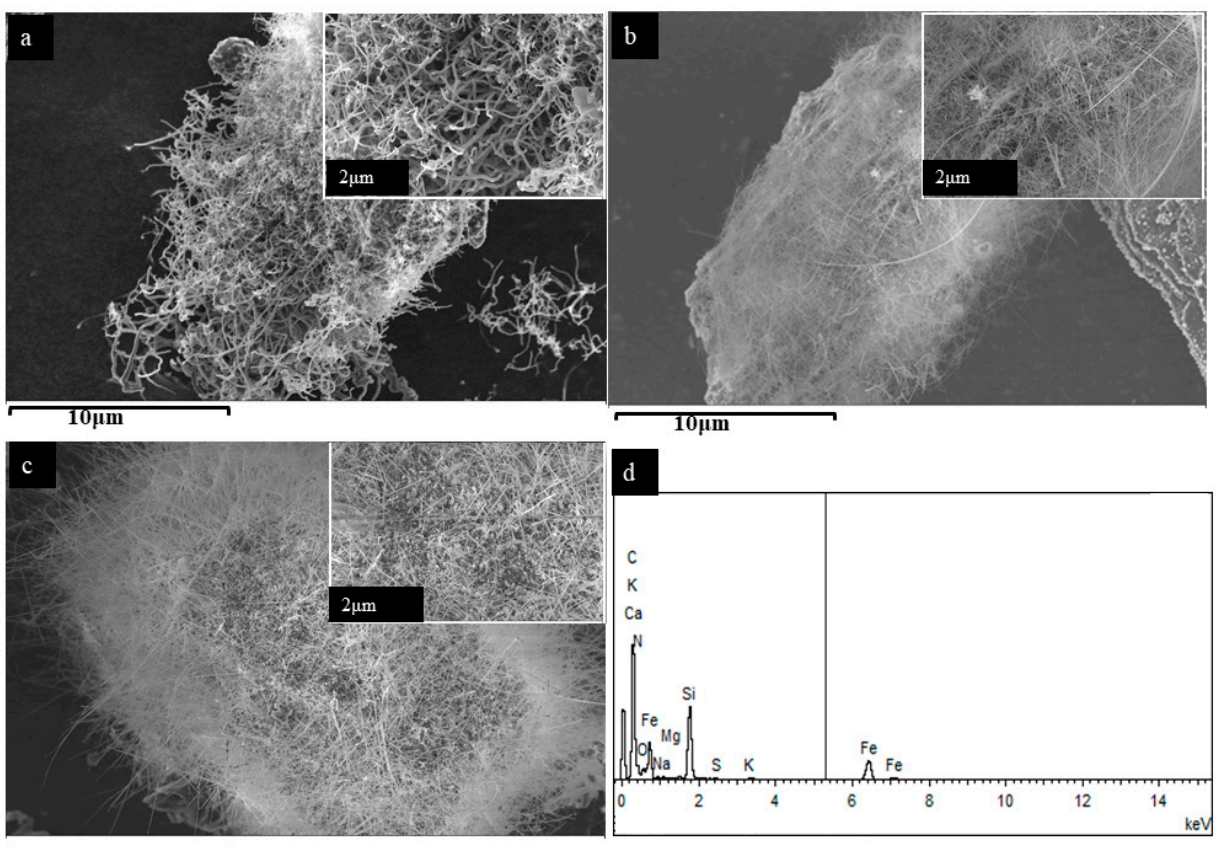

$10 \mu \mathrm{n}$

Figure 2. SEM images of SL-CNTs after microwave treatment: (a) $1200{ }^{\circ} \mathrm{C}$, (b) $1300{ }^{\circ} \mathrm{C}$, (c) $1400{ }^{\circ} \mathrm{C}$, (d) EDS spectra of SL-CNTs prepared at $1300^{\circ} \mathrm{C}$. Magnified images (insets; top right).
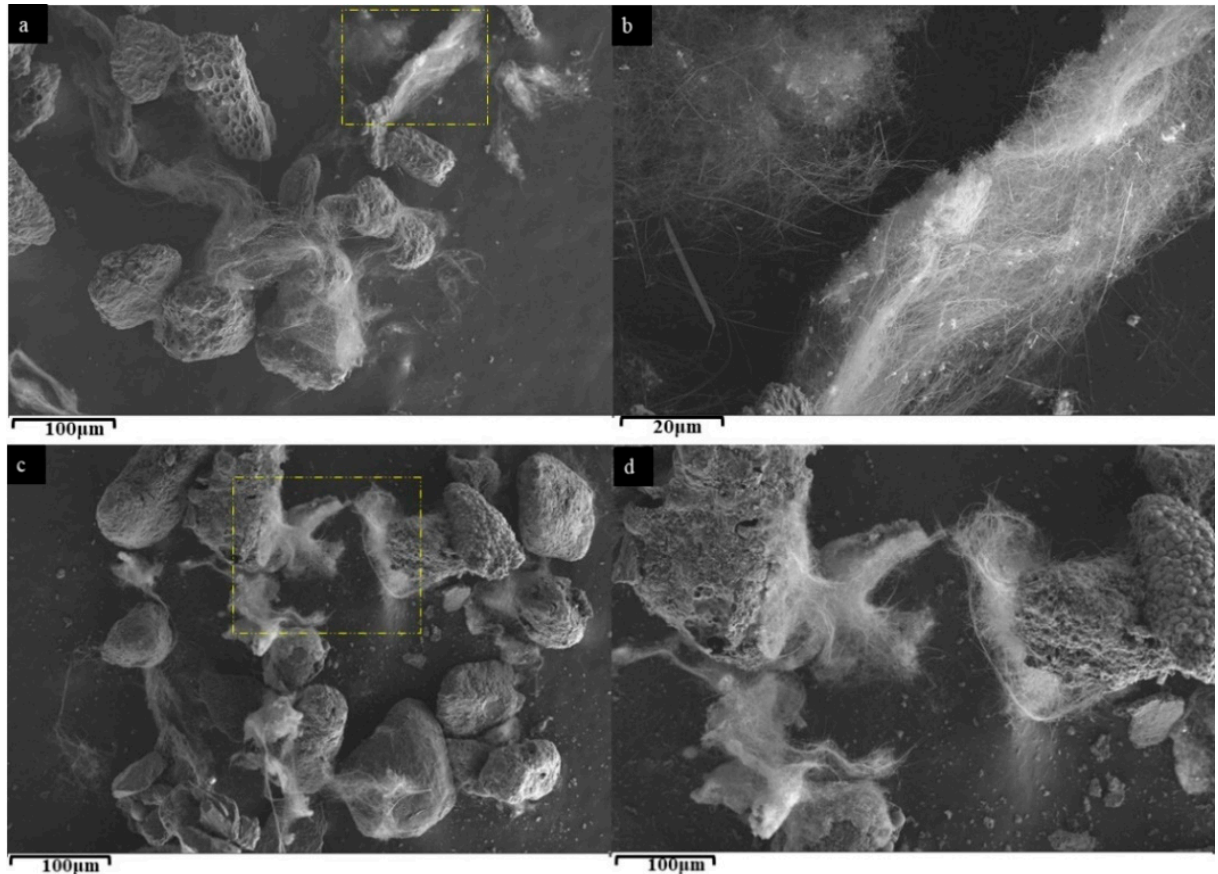

Figure 3. SEM images of (a) SL-CNTs used for length measurements, (b) magnified image of mapped out section in (a), (c) SL-CNTs on different particles, (d) magnified image of mapped out section in (c). 
Table 2. Length measurements of SL-CNTs from ImageJ analysis.

\begin{tabular}{ccccc}
\hline Mean & StdDev & Min & Max & Length (mm) \\
\hline 87.82 & 36.55 & 40.08 & 194.35 & 1.06 \\
93.29 & 30.42 & 46.14 & 183.45 & 0.77 \\
79.10 & 23.81 & 41.00 & 180.00 & 1.27 \\
89.94 & 37.62 & 33.26 & 226.56 & 0.91 \\
79.65 & 42.55 & 30.49 & 255.00 & 1.80 \\
70.34 & 39.25 & 29.13 & 252.49 & 2.23 \\
\hline
\end{tabular}

The EDS results of the SL-CNTs at $1400{ }^{\circ} \mathrm{C}$ (Figure 2d) revealed $\mathrm{Si}, \mathrm{Ca}, \mathrm{Mg}, \mathrm{Fe}, \mathrm{Na}$, and $\mathrm{K}$ [39]. These results suggested that the presence of inherent metallic species in biomass may have catalyzed the growth of the CNTs under high-temperature microwave treatment conditions [24].

The HRTEM analysis of the SL-CNTs after microwave treatment at $1200^{\circ} \mathrm{C}$ and $1300^{\circ} \mathrm{C}$ is shown in Figure 4. Some CNTs exhibited curved morphology (Figure 4a), while others had a vertical structure (Figure $4 \mathrm{~d}$ ). This may have resulted from the interaction between microwave irradiation and CNTs at high temperatures. The thermal effect of microwave treatment at elevated temperatures induces changes in the curved structure of CNTs in the presence of inherent inorganic matter in CNTs, thereby changing the morphology.

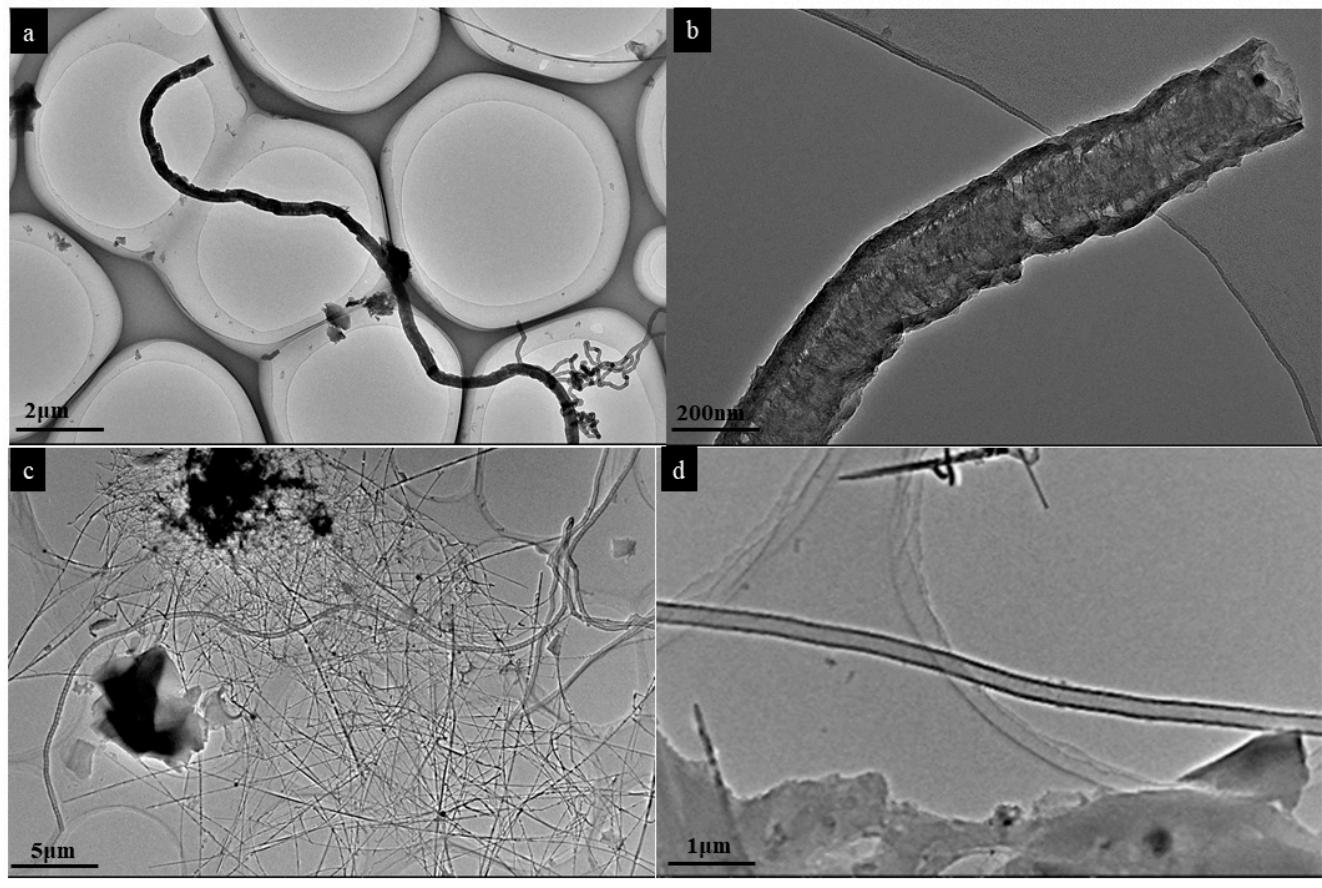

Figure 4. HRTEM images of CNTs after microwave treatment: (a) $1200{ }^{\circ} \mathrm{C}$, (b) magnified image of (a), (c) $1300{ }^{\circ} \mathrm{C},(\mathbf{d})$ magnified image of (c).

Figure 5 shows the hollow structure of CNTs. The $d$-spacing value of $0.32 \mathrm{~nm}$ was calculated for CNTs, slightly lower than that of natural graphite $(0.335 \mathrm{~nm})$. Figure $5 \mathrm{~b}$ shows that thick graphene layers formed bridges between the walls of CNTs. The changes in the structure of CNTs were attributed to the high mobility of carbon atoms at elevated temperatures [40,41]. This implies that structural change in SL-CNTs can be obtained under microwave treatment at high temperatures even though the CNTs initially had a different structure at lower temperatures. 


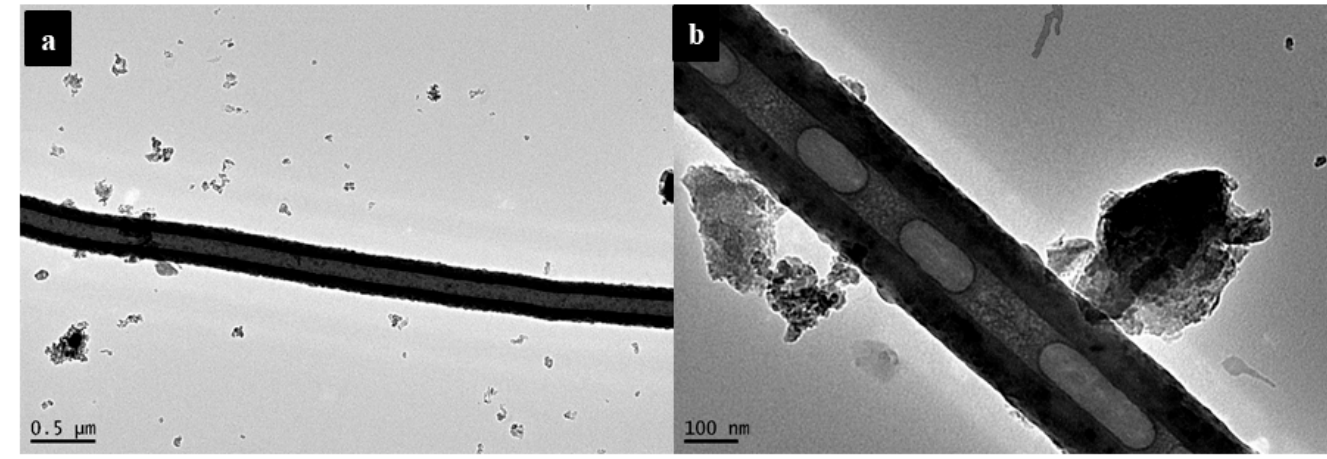

Figure 5. HR-TEM images of SL-CNTs synthesized at $1400^{\circ} \mathrm{C}$ : (a) and (b) show different magnifications.

\subsection{Crystalline Structure of CNTs}

The typical peaks for CNTs in XRD spectra are generally detected at $2 \theta=26^{\circ}$ and $2 \theta=43^{\circ}$, which illustrate the graphite (002) and (100) reflections, respectively [24]. Figure 6 shows two prominent peaks at $2 \theta=26.3^{\circ}$ and $2 \theta=43.2^{\circ}$ in the XRD spectra of CNTs after microwave treatment, suggesting that the CNTs possessed crystalline structure. The peak at $2 \theta=43.2^{\circ}$ was not detected at $600{ }^{\circ} \mathrm{C}$. However, after high-temperature microwave treatment, the peak became prominent. This is attributed to the increased carbon order of CNTs and a graphitic structure at higher temperatures. Si and Fe were observed in the CNT sample as their corresponding peaks were detected in the XRD spectra.

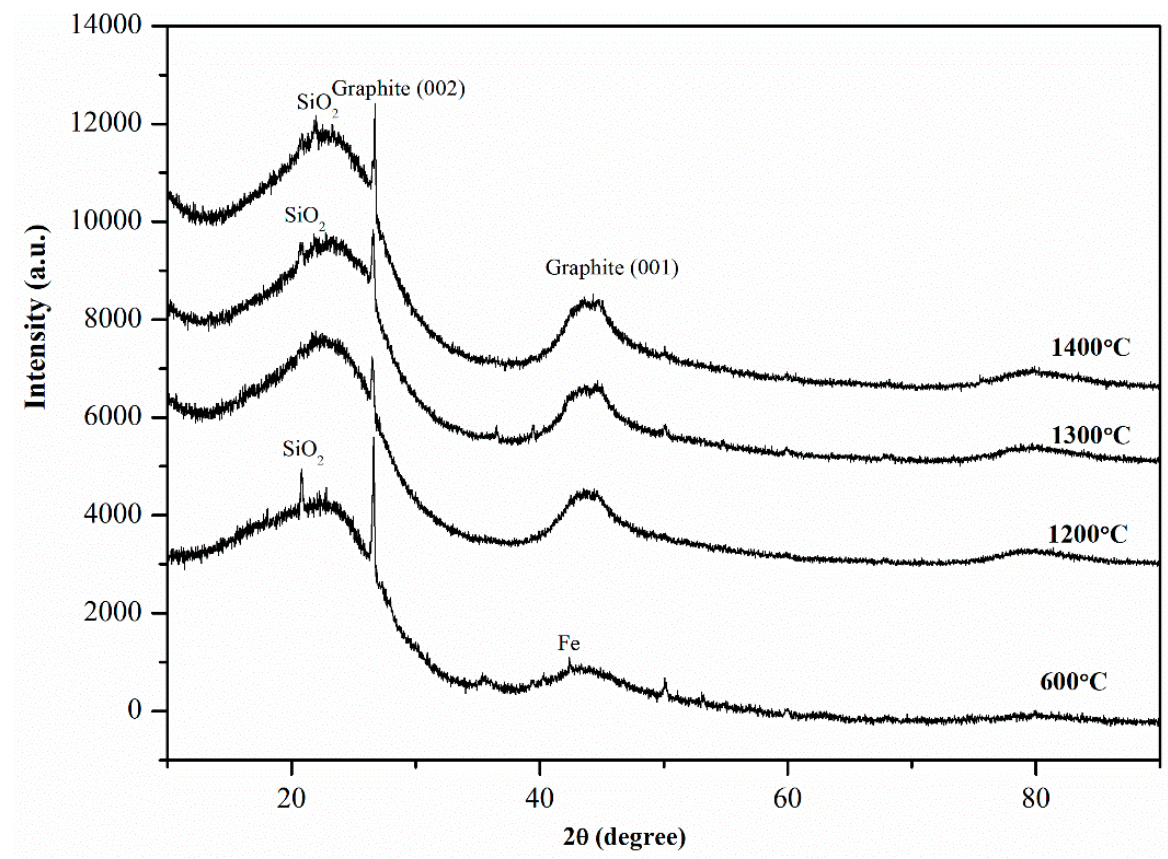

Figure 6. X-ray diffraction spectra of CNTs after microwave treatment at different temperatures.

To quantify the yield of SL-CNTs, the crystallinity of biochar samples was analyzed using Rietveld refinement quantitative analysis. The approach reported in [35] was used in this study. The results showed that the yield of CNTs increased from $9.81 \mathrm{wt} . \%$ at $600{ }^{\circ} \mathrm{C}$ to $17.32 \mathrm{wt} . \%, 23.54 \mathrm{wt} . \%$, and $24.89 \mathrm{wt} . \%$ at $1200{ }^{\circ} \mathrm{C}, 1300{ }^{\circ} \mathrm{C}$, and $1400{ }^{\circ} \mathrm{C}$, respectively. These results imply that the high-temperature microwave treatment substantially enhanced the yield of CNTs without the need for additional catalysts or carbon sources to be used.

\subsection{Changes in the Carbon Order of CNTs}

Raman spectra of the CNTs before and after high-temperature treatment is shown in Figure 7. Raman spectroscopy technique was used for investigating the degree of carbon 
order, the presence of defects, and the degree of crystallization [42,43]. The first-order Raman spectra of all samples displayed the typical bands that correlate with carbonaceous structures. The $\mathrm{G}$ band at $1590 \mathrm{~cm}^{-1}$ corresponds to the stretching mode in graphite planes associated with the $\mathrm{sp}^{2}$ bond. The $\mathrm{D}$ band at about $1360 \mathrm{~cm}^{-1}$ correlates with disorder and defects in highly ordered carbonaceous materials or graphite crystals [44,45]. As seen in Figure 6, the G band of the SL-CNTs increased with temperature, while the D band showed an opposite trend, implying that the degree of carbon order was increased at higher temperatures [46]. The $\mathrm{D}$ band intensity ratio to $\mathrm{G}$ band $\left(I_{D} / I_{G}\right)$ is a significant parameter for studying graphite-like or crystalline carbon structures. It indicates the degree of carbon order; a high ratio indicates a high defect in the carbon structure, while a lower ratio signifies a high carbon order and lower defect in the carbon structure [47]. The $I_{D} / I_{G}$ ratio is commonly used to evaluate the degree of graphitization in carbon materials like CNTs. The $I_{D} / I_{G}$ ratio of CNTs decreased from 0.97 at $1200{ }^{\circ} \mathrm{C}$ to 0.87 at $1300{ }^{\circ} \mathrm{C}$, finally to 0.84 at $1400{ }^{\circ} \mathrm{C}$. These results show that the carbon order and graphitization degree of SL-CNTs increased at elevated temperatures.

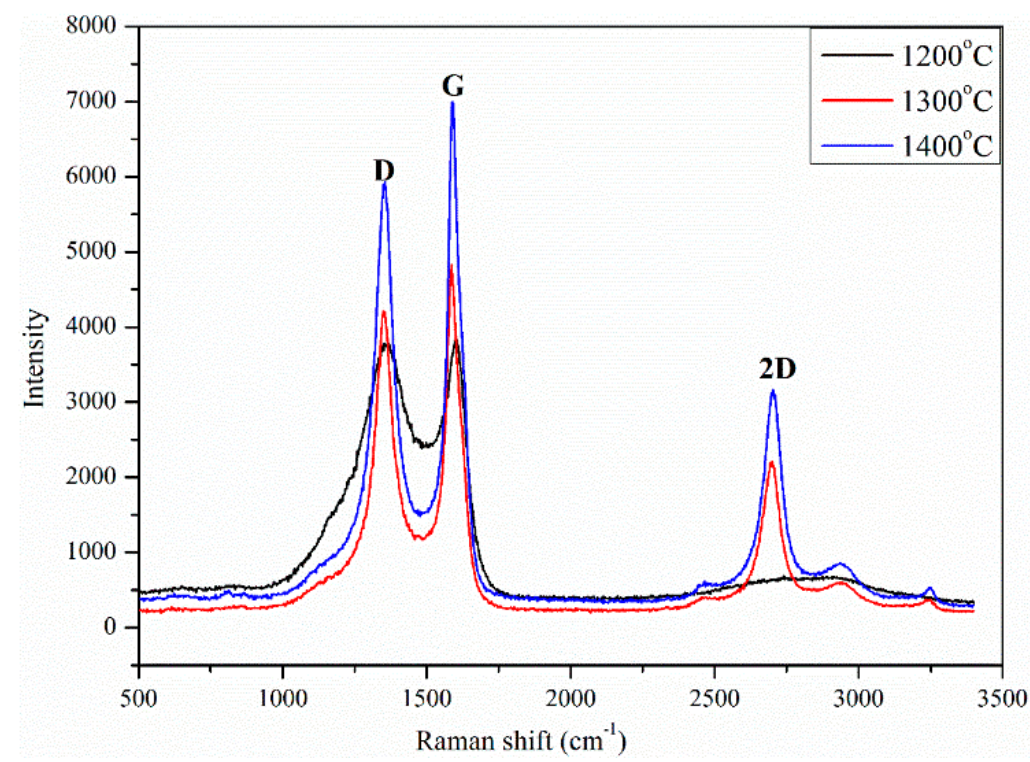

Figure 7. Raman spectra of SL-CNTs as a function of synthesis temperature.

To better understand the alteration in the microstructure of CNTs after microwave treatment, further analysis was carried out by deconvoluting the Raman spectra of the SL-CNTs into five bands by adopting the Gaussian function method. The additional bands at $1196 \mathrm{~cm}^{-1}$ (R1), 1635 (R2) $\mathrm{cm}^{-1}$, and $1515 \mathrm{~cm}^{-1}$ (R3) were considered. Aromatic carbon, aromatic ethers, and alkyl carbon bonds are linked to the R1 band [48]. The $\mathrm{R} 2$ band corresponds to the disordered structures of CNTs. The R3 band represents the functional groups in carbonaceous materials [49]. The area proportions of the deconvoluted Raman spectra of the SL-CNTs after microwave treatment are shown in Table 3. Noticeable changes were observed in the area of different bands with changes in temperature. An increase in the $\mathrm{G}$ band was evident at higher temperatures, indicating the transformation of amorphous carbon to graphitic carbon. The decrease in the R1 and R3 bands indicated the removal of organic structures and functional groups from the structure of CNTs at elevated temperatures under microwave treatment conditions. 
Table 3. Deconvoluted peaks area fraction as a function of pyrolysis temperature.

\begin{tabular}{cccccc}
\hline \multirow{2}{*}{$\begin{array}{c}\text { Temperature } \\
\left({ }^{\circ} \mathbf{C}\right)\end{array}$} & R1 & D & R3 & R2 & G \\
\cline { 2 - 6 } & 0.23 & 0.35 & 0.23 & 0.06 & 0.11 \\
1200 & 0.17 & 0.32 & 0.20 & 0.08 & 0.18 \\
1300 & 0.18 & 0.30 & 0.22 & 0.08 & 0.20 \\
1400 & & &
\end{tabular}

The integrated band area ratios were defined and used to better understand the changes in the carbon structure of SL-CNTs, and the results are shown in Figure 8. The $I_{R 2}+I_{R 3} / I_{D}$ ratio studied the formation of aromatic clusters during the growth of SL-CNTs. The amorphous carbon clusters containing 3-5 aromatic rings are represented by $I_{R 2}+I_{R 3}$, while $I_{D}$ reflects aromatic cluster development with more than six rings [50]. Figure 8 shows that the $I_{R 2}+I_{R 3} / I_{D}$ ratio of SL-CNTs decreased from 0.89 at $1200{ }^{\circ} \mathrm{C}$ to 0.70 at $1400{ }^{\circ} \mathrm{C}$, indicating the transformation of small aromatic systems to larger aromatic clusters, which in turn increased the carbon order of SL-CNTs. The monotonous increase in the $I_{G} / I_{A l l}$ ratio with temperature suggested that the graphitic structure of SL-CNTs was enhanced at higher temperatures. The $I_{R 1}+I_{R 3} / I_{G}$ ratio of SL-CNTs decreased from 1.60 at $1200{ }^{\circ} \mathrm{C}$ to 0.42 at $1400^{\circ} \mathrm{C}$. These results imply the removal of functional groups and the development of more ordered structures in SL-CNTs.

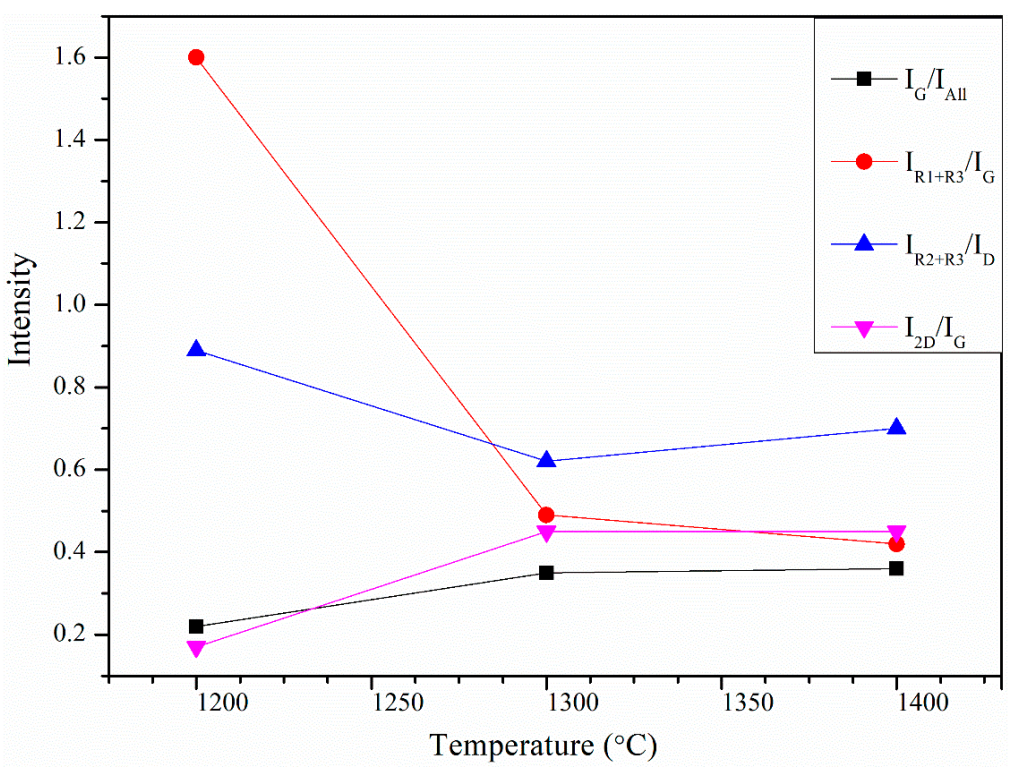

Figure 8. Band area ratio variations from the curve-fitting analysis of SL-CNTs Raman spectra as a function of temperature.

Figure 8 also shows that the intensity of the 2D band at $2678 \mathrm{~cm}^{-1}$ increased with temperature. This band is known as the overtone of the $\mathrm{D}$ band in the second-order Raman spectra. The shape, intensity, and frequency of the 2D band are affected by the chemical structure of CNTs and the number of carbon layers in the CNTs. The $I_{2 D} / I_{G}$ values of less than one in the SL-CNTs (Figure 8) indicated the development of multi-layered graphitic structures.

\subsection{Mechanism of Formation of SL-CNTs}

Based on the above results, the mechanism of the formation of SL-CNTs hinges on three factors, namely the catalytic role of the inherent minerals in the biomass, the unique effect of microwave heating, and the microwave treatment temperature. Inorganic matter in biomass can influence its decomposition behavior and the yield and composition of products $[39,51,52]$. We infer that the growth of SL-CNTs is a two-stage mechanism: 
(1) the formation of CNTs at low temperatures and (2) modification of structure and further growth under high-temperature microwave treatment. Based on the microwave heating mechanism, microwave energy is converted into heat when it penetrates the particle. The heat continues to accumulate in the particle core, leading to the formation of a temperature gradient. Due to internal pressure buildup, the generated volatile matter moves from the hot center to the particle's lower-temperature surface.

The first stage of this mechanism has been reported in our previous study [35]. Briefly, volatiles generated during the thermal decomposition of biomass form droplets on the particle's surface. The continuous release of volatiles, via self-extrusion from the nanopores, led to the growth of the CNTs. The EDS analysis showed minerals on the body and tip of the CNTs (Figure 1). Since no external catalyst was used, these elements are confirmed to originate from cellulose.

In the second stage, when the biochar containing CNTs was subjected to secondary heating under high microwave treatment at elevated temperature, pyrolysates from the biochar were generated. It served as a carbon source. These pyrolysates generated from the low-temperature biochar were the volatiles remaining in the char after pyrolysis (approximately $17 \mathrm{wt. \%}$ ). The volatiles left in the char were high molecular weight compounds that failed to generate enough vapor pressure to be released from the biomass [53]. These volatile materials were mainly composed of polyaromatic hydrocarbons (PAH), which acted as carbon sources for the growth SL-CNTs at elevated temperatures. The growth of SL-CNTs can occur through more than one route. We propose two possible routes of formation:

I. The CNTs formed at low temperature act as templates for the growth of the SL-CNTs. The tip of the CNT is known to be very reactive [54]. The volatiles released from the biochar at high-temperature form $\mathrm{PAH}$, which, in turn, adds graphene layers to the CNT tips, leading to the growth of the SL-CNTs. This agrees with the TEM results, which revealed an increase in the diameter after high-temperature treatment.

II. Through active sites in the char, which were activated by minerals or metals during high-temperature treatment. Char can be catalyzed by a trace amount of minerals that originate from the biomass. The minerals present in the char, notably Fe, produced a catalytic effect in the CNTs' growth. From previous investigations carried out by other researchers, CNTs can form, or even grow, in the presence of a meagre percentage of Fe catalyst [55]. The XRF analysis revealed at least $11.62 \mathrm{wt} . \%$ of Fe was present in the ash, as shown in Table 1. Due to the microwave's unique heating, at high temperature, volatiles released encapsulate the metal particle $(\mathrm{Fe})$ and elements present in the biomass char via surface or sub-surface diffusion. This process initiates the growth process by assembling carbon radicals into graphene around the element clusters, leading to the increased growth of SL-CNTs. This corresponds to the EDS analysis, where Fe and Si were observed on the SL-CNTs. The Fe was not visible in the XRD at a higher temperature because it was in low quantity and had high dispersion. Hence XRD could not identify some of its phases.

The change in the morphology of CNTs from curvy to straight may be attributed to the structural modification at high temperatures. Mobility of carbon atoms leads to re-orientating the carbon structure, and changes in its physical properties can occur at elevated temperatures [56,57]. In addition, the presence of the Si may affect the morphology changes, as $\mathrm{Si}$ is known to contribute to the formation of the straight-like morphology of nanotubes at elevated temperatures [39].

Table 4 shows the comparison between the SL-CNTs generated from this study in relation to those of SL-CNTs from other methods in the literature discussed in the Introduction. The main difference is the carbon source and the methods of synthesis. Biomass was used in this study, while other methods used gases from fossil fuels. In the synthesis method, microwave pyrolysis without a catalyst was used in this study, while other methods include CVD, laser ablation, arc discharge method, etc., with the aid of metallic catalysts. Structural 
defects were observed in the SL-CNTs synthesized in this study, as well as those reported in literature.

Table 4. Comparison between the SL-CNTs synthesized in this study and literature results.

\begin{tabular}{|c|c|c|}
\hline Synthesis Process/Parameters & Synthesized SL-CNTs in This Study & SL-CNTs Synthesized from Other Methods \\
\hline Carbon source & Volatiles in biomass & $\begin{array}{c}\text { Gases derived from fossil fuels (methane, } \\
\text { ethane, acetylene, etc.) }\end{array}$ \\
\hline Catalyst & No catalyst & metallic catalysts $(\mathrm{Ni}, \mathrm{Mo}, \mathrm{Fe}, \mathrm{Co}$, etc.) \\
\hline Process & Microwave synthesis & $\begin{array}{c}\text { Laser ablation, Arc discharge, CVD, CCVD, } \\
\text { PECVD }\end{array}$ \\
\hline Temperature & $600-1400^{\circ} \mathrm{C}$ & $700-2500^{\circ} \mathrm{C}$ \\
\hline Time & $30 \mathrm{~min}$ & Ranges from $1-10 \mathrm{~h}$ \\
\hline Length (mm) & $0.7-2$ & $1-5$ \\
\hline Morphology & Ordered carbon structure with some defect & Ordered carbon structure with some defect \\
\hline
\end{tabular}

\subsection{Implications of the Novel SL-CNTs Production Method}

Although carbon nanotubes are being used widely in various technological fields, they still have some significant drawbacks that hinder their full potential due to their small dimensions and the lifespan of added catalysts. Previously, SL-CNT formation was dependent on the catalyst's lifetime. The electrical and mechanical properties of CNTs can only be harnessed if the CNTs are long and continuous for some applications. This novel method of producing SL-CNTs is simple, safe, and environmentally friendly and an ethical approach towards synthesizing cleaner, high purity, and low-cost SL-CNTs from biomass without the need for an additional catalyst or carbon source under microwave treatment. Therefore, the method can provide a convenient means of producing selective CNT morphology, leading to the mass production of SL-CNTs on an economic basis. SL-CNTs pave the way for novel opportunities for capitalizing on CNT properties over large length scales. The SL-CNTs formed are more durable and possess strong electrical and mechanical properties, making them valuable for an increasingly large number of applications in the field of nanotechnology, material science, and even modern-day living. The advantages of SL-CNTs over their shorter counterparts include enhanced suitability for electrical conduction, multifunctional composites, sensors, and nanoelectronics. SL-CNTs offer a combination of flexibility, electrochemical reactivity, strength, electrical conductivity, and porosity, which will pave the way for a new era of technological advancement.

\section{Conclusions}

Super-long carbon nanotubes (SL-CNTs) with lengths of up to $2 \mathrm{~mm}$ were successfully synthesized from cellulose biomass via microwave treatment without any catalyst or external carbon source. A low Raman $\mathrm{I}_{\mathrm{D}} / \mathrm{I}_{\mathrm{G}}$ ratio of 0.84 after microwave treatment at $1400{ }^{\circ} \mathrm{C}$ was obtained, indicating an increase in the carbon order in the SL-CNTs. The yield of SL-CNTs reached $26.89 \mathrm{wt} . \%$ at $1400{ }^{\circ} \mathrm{C}$. The inherent inorganic matter in biomass was postulated to have functioned as a catalyst to facilitate the growth of the SL-CNTs. The carbon supply source for the SL-CNTs under microwave treatment was the aromatic hydrocarbons generated from the biochar. The change in the morphology and structure of CNTs after microwave treatment can be used to control the quality and structure of CNTs from cellulosic biomass. The method of SL-CNT synthesis presented here is a simple but sustainable method for the synthesis of nanotubes from renewable biomass without the use of any catalyst or external carbon source. Hence, this is a promising approach for large scale production of superlong carbon nanotubes that should find applications in various industries. 


\begin{abstract}
Author Contributions: Conceptualization, J.E.O., J.Y. and A.T.; methodology, J.E.O., J.Z. and A.T.; formal analysis, J.E.O. and J.Z.; writing-original draft preparation, J.E.O.; writing-review and editing, J.E.O., A.T. and J.Y.; super-vision, J.Y. and A.T.; project administration, J.Y. All authors have read and agreed to the published version of the manuscript.
\end{abstract}

Funding: This research has been financially supported by the National Natural Science Foundation of China (22078141).

Institutional Review Board Statement: Not applicable.

Informed Consent Statement: Not applicable.

Data Availability Statement: Data presented in this study are available in this article.

Acknowledgments: The authors gratefully acknowledge the financial support of the University of Science and Technology Liaoning Talent Project Grants (601011507-02).

Conflicts of Interest: The authors declare no conflict of interest.

\title{
References
}

1. Iijima, S. Helical microtubules of graphitic carbon. Nature 1991, 354, 56-58. [CrossRef]

2. $\quad$ Ghemes, C.; Ghemes, A.; Okada, M.; Inoue, Y.; Mimura, H. Synthesis of Long and Spinnable Multi-Walled Carbon Nanotubes. J. Adv. Res. Phys. 2012, 3, 011209.

3. Li, Q.W.; Zhang, X.F.; DePaula, R.F.; Zheng, L.X.; Zhao, Y.H.; Stan, L.; Holesinger, T.G.; Arendt, P.N.; Peterson, D.E.; Zhu, Y.T. Sustained Growth of Ultralong Carbon Nanotube Arrays for Fiber Spinning. Adv. Mater. 2006, 18, 3160-3163. [CrossRef]

4. Demczyk, B.G.; Wang, Y.M.; Cumings, J.; Hetman, M.; Han, W.; Zettl, A.; Ritchie, R.O. Direct mechanical measurement of the tensile strength and elastic modulus of multiwalled carbon nanotubes. Mater. Sci. Eng. 2002, 334, 173-178. [CrossRef]

5. Salvetat, J.-P.; Briggs, G.M.; Bonard, J.; Bacsa, R.; Kulik, A.; Stockli, T.; Burnham, N.; Forró, L. Elastic and Shear Moduli of Single-Walled Carbon Nanotube Ropes. Phys. Rev. Lett. 1999, 82, 944. [CrossRef]

6. Scott, C.D.; Arepalli, S.; Nikolaev, P.; Smalley, R.E. Growth mechanisms for single-wall carbon nanotubes in a laser-ablation process. Appl. Phys. A 2001, 72, 573-580. [CrossRef]

7. Yu, H.; Quan, X.; Chen, S.; Zhao, H. TiO2-Multiwalled Carbon Nanotube Heterojunction Arrays and Their Charge Separation Capability. J. Phys. Chem. C 2007, 111, 12987-12991. [CrossRef]

8. Xu, X.; Huang, S.; Hu, Y.; Lu, J.; Yang, Z. Continuous synthesis of carbon nanotubes using a metal-free catalyst by CVD. Mater Chem. Phys. 2012, 133, 95-102. [CrossRef]

9. Cho, W.; Schulz, M.; Shanov, V. Growth and characterization of vertically aligned centimeter long CNT arrays. Carbon 2014, 72, 264-273. [CrossRef]

10. Ebbesen, T.W.; Ajayan, P.M. Large-scale synthesis of carbon nanotubes. Nature 1992, 358, 220-222. [CrossRef]

11. Lim, S.; Luo, Z.; Shen, Z.; Lin, J. Plasma-Assisted Synthesis of Carbon Nanotubes. Nanoscale Res. Lett. 2010, 5, 1377-1386. [CrossRef] [PubMed]

12. Liu, K.; Sun, Y.; Chen, L.; Feng, C.; Feng, X.; Jiang, K.; Zhao, Y.; Fan, S. Controlled Growth of Super-Aligned Carbon Nanotube Arrays for Spinning Continuous Unidirectional Sheets with Tunable Physical Properties. Nano Lett. 2008, 8, 700-705. [CrossRef] [PubMed]

13. Xu, X.; Huang, S.; Yang, Z.; Zou, C.; Jiang, J.; Shang, Z. Controllable synthesis of carbon nanotubes by changing the Mo content in bimetallic Fe-Mo/MgO catalyst. Mater. Chem. Phys. 2011, 127, 379-384. [CrossRef]

14. Aboul-Enein, A.A.; Awadallah, A.E. Impact of $\mathrm{Co} / \mathrm{Mo}$ ratio on the activity of CoMo/MgO catalyst for production of high-quality multi-walled carbon nanotubes from polyethylene waste. Mater. Chem. Phys. 2019, 238, 121879. [CrossRef]

15. Lee, C.-H.; Lee, J.; Park, J.; Lee, E.; Kim, S.M.; Lee, K.-H. Rationally designed catalyst layers toward "immortal" growth of carbon nanotube forests: Fe-ion implanted substrates. Carbon 2019, 152, 482-488. [CrossRef]

16. Lee, J.; Oh, E.; Kim, T.; Sa, J.-H.; Lee, S.-H.; Park, J.; Moon, D.; Kang, I.S.; Kim, M.J.; Kim, S.M.; et al. The influence of boundary layer on the growth kinetics of carbon nanotube forests. Carbon 2015, 93, 217-225. [CrossRef]

17. Calgaro, C.O.; Perez-Lopez, O.W. Graphene and carbon nanotubes by CH4 decomposition over CoAl catalysts. Mater. Chem. Phys. 2019, 226, 6-19. [CrossRef]

18. Zhu, H.W.; Xu, C.L.; Wu, D.H.; Wei, B.Q.; Vajtai, R.; Ajayan, P.M. Direct Synthesis of Long Single-Walled Carbon Nanotube Strands. Science 2002, 296, 884. [CrossRef]

19. Snow, E.S.; Perkins, F.K.; Houser, E.J.; Badescu, S.C.; Reinecke, T.L. Chemical Detection with a Single-Walled Carbon Nanotube Capacitor. Science 2005, 307, 1942. [CrossRef]

20. Qu, L.; Peng, Q.; Dai, L.; Spinks, G.M.; Wallace, G.G.; Baughman, R.H. Carbon Nanotube Electroactive Polymer Materials: Opportunities and Challenges. MRS Bull. 2011, 33, 215-224. [CrossRef]

21. Bachtold, A.; Hadley, P.; Nakanishi, T.; Dekker, C. Logic Circuits with Carbon Nanotube Transistors. Science 2001, $294,1317$. [CrossRef] [PubMed] 
22. Chen, Z.; Appenzeller, J.; Lin, Y.-M.; Sippel-Oakley, J.; Rinzler, A.G.; Tang, J.; Wind, S.J.; Solomon, P.M.; Avouris, P. An Integrated Logic Circuit Assembled on a Single Carbon Nanotube. Science 2006, 311, 1735. [CrossRef] [PubMed]

23. Veedu, V.P.; Cao, A.; Li, X.; Ma, K.; Soldano, C.; Kar, S.; Ajayan, P.M.; Ghasemi-Nejhad, M.N. Multifunctional composites using reinforced laminae with carbon-nanotube forests. Nat. Mater. 2006, 5, 457-462. [CrossRef] [PubMed]

24. Ajayan, P.M.; Tour, J.M. Nanotube composites. Nature 2007, 447, 1066. [CrossRef]

25. Zhao, Y.; Hu, Y.; Li, Y.; Zhang, H.; Zhang, S.; Qu, L.; Shi, G.; Dai, L. Super-long aligned TiO2/carbon nanotube arrays. Nanotechnology 2010, 21, 505702. [CrossRef]

26. Sugime, H.; Sato, T.; Nakagawa, R.; Hayashi, T.; Inoue, Y.; Noda, S. Ultra-long carbon nanotube forest via in situ supplements of iron and aluminum vapor sources. Carbon 2021, 172, 772-780. [CrossRef]

27. Chakrabarti, S.; Gong, K.; Dai, L. Structural Evaluation along the Nanotube Length for Super-long Vertically Aligned DoubleWalled Carbon Nanotube Arrays. J. Phys. Chem. C 2008, 112, 8136-8139. [CrossRef]

28. Chakrabarti, S.; Kume, H.; Pan, L.; Nagasaka, T.; Nakayama, Y. Number of Walls Controlled Synthesis of Millimeter-Long Vertically Aligned Brushlike Carbon Nanotubes. J. Phys. Chem. C 2007, 111, 1929-1934. [CrossRef]

29. Loiseau, A.; Pascard, H. Synthesis of long carbon nanotubes filled with Se, S, Sb and Ge by the arc method. Chem. Phys. Lett. 1996, 256, 246-252. [CrossRef]

30. Wondong, C.; Schulz, M.; Shanov, V. Kinetics of Growing Centimeter Long Carbon Nanotube Arrays. In Syntheses and Applications of Carbon Nanotubes and Their Composites, Satoru Suzuki; IntechOpen; Available online: https://www.intechopen.com/ books/syntheses-and-applications-of-carbon-nanotubes-and-their-composites/kinetics-of-growing-centimeter-long-carbonnanotube-arrays (accessed on 15 October 2019).

31. Omoriyekomwan, J.E.; Tahmasebi, A.; Dou, J.; Tian, L.; Yu, J. Mechanistic study on the formation of silicon carbide nanowhiskers from biomass cellulose char under microwave. Mater. Chem. Phys. 2021, 262, 124288. [CrossRef]

32. Zhao, X.; Li, W.; Kong, F.; Chen, H.; Wang, Z.; Liu, S.; Jin, C. Carbon spheres derived from biomass residue via ultrasonic spray pyrolysis for supercapacitors. Mater. Chem. Phys. 2018, 219, 461-467. [CrossRef]

33. Zou, Z.; Liu, T.; Jiang, C. Highly mesoporous carbon flakes derived from a tubular biomass for high power electrochemical energy storage in organic electrolyte. Mater. Chem. Phys. 2019, 223, 16-23. [CrossRef]

34. Liu, P.; Wang, Y.; Liu, J. Biomass-derived porous carbon materials for advanced lithium sulfur batteries. J. Energy Chem. 2019, 34, 171-185. [CrossRef]

35. Omoriyekomwan, J.E.; Tahmasebi, A.; Zhang, J.; Yu, J. Mechanistic study on direct synthesis of carbon nanotubes from cellulose by means of microwave pyrolysis. Energy Convers. Manag. 2019, 192, 88-99. [CrossRef]

36. Bengio, E.A.; Tsentalovich, D.E.; Behabtu, N.; Kleinerman, O.; Kesselman, E.; Schmidt, J.; Talmon, Y.; Pasquali, M. Statistical Length Measurement Method by Direct Imaging of Carbon Nanotubes. ACS Appl. Mater. Interfaces 2014, 6, 6139-6146. [CrossRef]

37. Sandoval, S.; Kierkowicz, M.; Pach, E.; Ballesteros, B.; Tobias, G. Determination of the length of single-walled carbon nanotubes by scanning electron microscopy. MethodsX 2018, 5, 1465-1472. [CrossRef]

38. Tajima, R.; Kato, Y. [Short Report] A Quick Method to Estimate Root Length in Each Diameter Class Using Freeware ImageJ. Plant Prod. Sci. 2013, 16, 9-11. [CrossRef]

39. Zhu, J.; Jia, J.; Kwong, F.L.; Ng, D.H.L.; Tjong, S.C. Synthesis of multiwalled carbon nanotubes from bamboo charcoal and the roles of minerals on their growth. Biomass Bioenergy 2012, 36, 12-19. [CrossRef]

40. Behler, K.; Osswald, S.; Ye, H.; Dimovski, S.; Gogotsi, Y. Effect of Thermal Treatment on the Structure of Multi-walled Carbon Nanotubes. J. Nanoparticle Res. 2006, 8, 615-625. [CrossRef]

41. Pham, Q.N.; Larkin, L.S.; Lisboa, C.C.; Saltonstall, C.B.; Qiu, L.; Schuler, J.D.; Rupert, T.J.; Norris, P.M. Effect of growth temperature on the synthesis of carbon nanotube arrays and amorphous carbon for thermal applications. Phys. Status Solidi 2017, 214, 1600852. [CrossRef]

42. Mubarak, N.M.; Sahu, J.N.; Abdullah, E.C.; Jayakumar, N.S.; Ganesan, P. Single stage production of carbon nanotubes using microwave technology. Diam. Relat. Mater. 2014, 48, 52-59. [CrossRef]

43. Bai, J.; Huang, Y.; Gong, Q.; Liu, X.; Li, Y.; Gan, J.; Zhao, M.; Shao, Y.; Zhuang, D.; Liang, J. Preparation of porous carbon nanotube/carbon composite spheres and their adsorption properties. Carbon 2018, 137, 493-501. [CrossRef]

44. Jiménez, F.; Mondragón, F.; López, D. Structural changes in coal chars after pressurized pyrolysis. J. Anal. Appl. Pyrolysis 2012, 95, 164-170. [CrossRef]

45. Li, X.; Hayashi, J.-i.; Li, C.-Z. FT-Raman spectroscopic study of the evolution of char structure during the pyrolysis of a Victorian brown coal. Fuel 2006, 85, 1700-1707. [CrossRef]

46. Omoriyekomwan, J.E.; Tahmasebi, A.; Zhang, J.; Yu, J. Formation of hollow carbon nanofibers on bio-char during microwave pyrolysis of palm kernel shell. Energy Convers. Manag. 2017, 148, 583-592. [CrossRef]

47. Zhang, J.; Tahmasebi, A.; Omoriyekomwan, J.E.; Yu, J. Direct synthesis of hollow carbon nanofibers on bio-char during microwave pyrolysis of pine nut shell. J. Anal. Appl. Pyrolysis 2018, 130, 142-148. [CrossRef]

48. $\mathrm{Li}, \mathrm{C}$.-Z. Some recent advances in the understanding of the pyrolysis and gasification behaviour of Victorian brown coal. Fuel 2007, 86, 1664-1683. [CrossRef]

49. Sadezky, A.; Muckenhuber, H.; Grothe, H.; Niessner, R.; Pöschl, U. Raman microspectroscopy of soot and related carbonaceous materials: Spectral analysis and structural information. Carbon 2005, 43, 1731-1742. [CrossRef] 
50. Bai, Y.; Wang, Y.; Zhu, S.; Li, F.; Xie, K. Structural features and gasification reactivity of coal chars formed in Ar and CO2 atmospheres at elevated pressures. Energy 2014, 74, 464-470. [CrossRef]

51. Shi, K. Catalyst-Free Synthesis of Multiwalled Carbon Nanotubes via Microwave-Induced Processing of Biomass. Ind. Eng.Chem. Res. 2014, 53, 15012-15019. [CrossRef]

52. Yang, H.; Yan, R.; Chen, H.; Zheng, C.; Lee, D.H.; Liang, D.T. Influence of mineral matter on pyrolysis of palm oil wastes. Combust. Flame 2006, 146, 605-611. [CrossRef]

53. Huang, Y.; Hu, Y.; Hayashi, J.-i.; Fang, Y. Interactions between Volatiles and Char during Pyrolysis of Biomass: Reactive Species Determining and Reaction over Functionalized Carbon Nanotubes. Energy Fuels 2016, 30, 5758-5765. [CrossRef]

54. Lin, T.; Bajpai, V.; Ji, T.; Dai, L. Chemistry of Carbon Nanotubes. ChemInform 2003, 56, 635-651. [CrossRef]

55. Chen, X.-W.; Timpe, O.; Hamid, S.B.A.; Schlögl, R.; Su, D.S. Direct synthesis of carbon nanofibers on modified biomass-derived activated carbon. Carbon 2009, 47, 340-343. [CrossRef]

56. Castillejos, E.; Bachiller-Baeza, B.; Pérez-Cadenas, M.; Gallegos-Suarez, E.; Rodríguez-Ramos, I.; Guerrero-Ruiz, A.; TamargoMartinez, K.; Martinez-Alonso, A.; Tascón, J.M.D. Structural and surface modifications of carbon nanotubes when submitted to high temperature annealing treatments. J. Alloys Compd. 2012, 536, S460-S463. [CrossRef]

57. Bougrine, A.; Dupont-Pavlovsky, N.; Naji, A.; Ghanbaja, J.; Marêché, J.F.; Billaud, D. Influence of high temperature treatments on single-walled carbon nanotubes structure, morphology and surface properties. Carbon 2001, 39, 685-695. [CrossRef] 